The Wisdom in Virtue: Pursuit of Virtue Predicts Wise Reasoning about Personal Conflicts

\author{
Alex C. Huynh", Harrison Oakes, Garrett Shay \& Ian McGregor \\ University of Waterloo
}

In press in Psychological Science

*Whom the correspondence should be addressed at:

200 University Avenue West, Waterloo, Ontario, Canada N2L 3G1

E-mail: alex.huynh@uwaterloo.ca 


\begin{abstract}
Most people can reason relatively wisely about others' social conflicts, but often struggle to do so about their own (i.e., Solomon's Paradox; Grossmann \& Kross, 2014). We suggest that true wisdom should involve the ability to reason wisely about others' and one's own social conflicts. The present studies investigate the pursuit of virtue as a construct that predicts this broader capacity for wisdom. Results across two studies support prior Solomon's Paradox findings: participants $(N=623)$ expressed greater wisdom (e.g., intellectual humility, adopting outsider's perspectives) about others' social conflicts than their own. The pursuit of virtue (e.g., pursuing personal ideals and contributing to others) moderated these results. In both studies, high virtue pursuit was associated with a greater endorsement of wise reasoning strategies for one's own personal conflicts, reducing the discrepancy in wise reasoning between one's own and others' social conflicts. Implications and mechanisms are explored and discussed.
\end{abstract}

Keywords: Wisdom, Virtue, Motivation, Interpersonal Conflicts, Well-being 


\section{The Wisdom in Virtue: Pursuit of Virtue Predicts Wise Reasoning about Personal Conflicts}

Wisdom is broadly defined as the flexible and appropriate application of pragmatic reasoning to social life challenges (Baltes \& Smith, 2008; Levenson, Jennings, Aldwin, \& Shiraishi, 2005; Staudinger \& Glück, 2011; for review of definitions, see Grossmann et al., 2017). Philosophers have long tied this conceptualization of wisdom with virtue, proposing that pursuing virtue and wisdom are core facets of the good life (Kraut, 2016). For example, the virtue of prudence — defined by Aristotle as recta ratio agibilium, "right reason applied to practice" (Delany, 1911) — is referenced as the virtue of wisdom and ranked by St. Thomas Aquinas as the first of four cardinal virtues (Aquinas, n.d./2012). Despite past suppositions by philosophers and psychologists that wisdom and virtue are linked, no research to our knowledge has offered an empirical assessment of whether pursuing virtue is a hallmark of wise character.

We propose that the litmus test for wise character is reflected in one's capacity to reason wisely about one's own social conflicts. Like the biblical King Solomon, people tend to reason more wisely over others' social conflicts than their own (i.e., Solomon's Paradox; Grossmann \& Kross, 2014, see also Mickler \& Staudinger, 2008, for personal vs. general wisdom). Personal conflicts impede wise reasoning because people are more likely to immerse themselves in their own perspective and emotions, relegating other perspectives out of awareness, and increasing certainty over preferred perspectives (McGregor, Zanna, Holmes, \& Spencer, 2001; Kross \& Grossmann, 2012). In contrast, reasoning over others' conflicts facilitates wise reasoning through the adoption of different viewpoints, and the avoidance of socio-cognitive biases (e.g., poor recognition of one's own shortcomings, e.g., Pronin, Olivola, \& Kennedy, 2008). In the present research, we investigate whether virtuous motives facilitate wisdom about one's own conflicts, enabling individuals to pass the litmus test for wise character. 
Wisdom and Virtue. In accordance with philosophers who spoke of wisdom and virtue as inextricably linked, researchers acknowledge that virtuous motives are a central component of wisdom (e.g., Baltes \& Staudinger, 2000). In the psychological literature, wisdom and virtue are often juxtaposed, with both being said to encourage greater empathy, selflessness, and compassion (Le, 2011; Dambrun \& Ricard, 2011). Yet, despite the two concepts often being discussed together, little has been done to explore exactly how virtue may be related to wisdom.

Contemporary operationalizations of wisdom suggest it is comprised of multiple subcomponents (e.g., intellectual humility, perspective-taking, search for compromise; recognition of change; Grossmann et al., 2010). In limited work thus far, research suggests that virtue may be able to promote several of wisdom's subcomponents. For example, those who expressed virtuous motives - defined as a desire to act beyond personal interests and develop the best in oneself - were also more likely to minimize self-focus (Huta \& Ryan, 2010), and express greater growth and insight after difficult life experiences (Bauer, McAdams \& Pals, 2008). Further, research by Kunzmann \& Baltes (2003) found that wisdom-related knowledge is positively associated with the importance of personal growth and the well-being of others. These findings suggest that pursuing virtue reduces a focus on egocentric views, and increases the value of others' unique experiences and perspectives, both central tenets of wise reasoning (Grossmann, Na, Varnum, Kitayama, \& Nisbett, 2013). If this is true, then pursuing virtue should encourage the recognition that one's personal perspectives may not be enough to fully understand a conflict, promoting wisdom about one's own conflicts as well as others'.

Research Overview. The first goal of the present studies was to replicate Solomon's Paradox, demonstrating that people tend to reason more wisely about others' conflicts than their own. Our second goal was to test our hypothesis that the pursuit of virtue will promote equally 
wise reasoning about self and other-conflicts. Our third goal was to explore the relationship between virtue and specific wisdom subcomponents (Grossman et al., 2010), providing insight into the underlying mechanisms behind virtue's relation to wisdom for personal conflicts.

\section{Study 1}

\section{Method}

Participants. Based on effect sizes from prior research on Solomon's Paradox (Grossmann \& Kross, 2014) a G*power analysis suggested a total sample size of approximately 275 participants. We aimed to hit this target, while obtaining as large of a sample as we could and recruited 333 undergraduate students from York University during the winter academic term of 2015. All participants completed this study for course credit. Throughout the study, participants were assessed for attentiveness to the study, for example, participants answered "I sometimes just clicked random responses" on a scale from 1 (none of the time) to 5 (all of the time). Those who indicated they were inattentive "most of the time" or more were excluded from the study. The final sample consisted of 267 participants (188 females; mean age $=21.76$ years, $S D=4.51)$

Procedure and Materials. Participants were brought into the lab as part of a larger study on personality and motivation. The measures relevant to our analyses were presented in a segment near the beginning of this larger study. Prior to the measures we report in this study, participants were randomly assigned to an approach- or avoidance-motivation condition. We analyzed this manipulation's impact on our manipulation and measures of interest and found that it did not significantly predict any of the measures in our study, nor did it interact significantly with our manipulation on these variables, all $F_{\mathrm{S}}<1.31$ (see SOM-R for further analyses and details). As this manipulation did not interact with our primary manipulation, we do not discuss it further here. The results of our study do not differ when including the manipulation as a 
covariate, so we present results without its inclusion in the model.

Following the manipulation of motivational state, participants reported their pursuit of virtue. Participants were then randomly assigned to report on either a personal conflict they were involved in (self-conflicts; $n=136$ ), or a conflict that a close friend was involved in (otherconflicts; $n=131)$ :

“Think about a [friend's] close relationship (family member, friend, or romantic partner) that is currently not going very well. [This must be a relationship that you are not involved in.] For example, you [your friend] may be fighting a lot lately, or may not be talking as much as you [they] used to [in his or her relationship]. You are [Your friend is] uncertain as to whether you [he/she] will be able to continue to be as close to this person in the future."

Participants then indicated the type of relationship it was that they or their friends had a conflict in (e.g., romantic, familial, or friendship). For self-conflicts, $16.2 \%$ of participants indicated the conflict was with a romantic partner, $37.5 \%$ with family members, $44.1 \%$ with friends, and 2.2\% were unspecified. For their friend's conflicts, 30.5\% reflected on conflicts that their close friends were having with their romantic partners, $30.5 \%$ with their family members, $37.4 \%$ with their friends, and $1.5 \%$ were unspecified. Following these indications, participants were given 90 seconds to describe the specific problems and difficulties associated with the conflict. Participants were then asked to imagine the conflict continuing to go poorly, or perhaps getting worse. To experientially involve participants in their conflicts, they were given an additional 90 seconds to describe their thoughts and feelings about the situation. This procedure did not provide an opportunity for participants to express reasoning strategies. To assess reasoning, we utilized the wise-reasoning scale, described below, which referred participants back to this conflict.

Pursuit of Virtue. Participants completed a state-modified version of the Hedonic and Eudaimonic Motives for Activities scale (HEMA; Huta \& Ryan, 2010), assessing their pursuit of 
virtue. Participants rated their agreement with five virtue statements: i. I would like to pursue excellence or a personal ideal; ii. I would like to contribute to others or the surrounding world; iii. I would like to do what I believe in; iv. I would like to use the best in myself; and v. I would like to develop a skill, learn, or gain insight into something; $M=4.43 ; S D=.55, \alpha=.83$ ). The scale also included five hedonic motivation statements (e.g., I would like to have fun; I would like to take it easy; $M=4.34, S D=.54, \alpha=.75$ ). As hedonic motivation and the pursuit of virtue are considered related motivational constructs (e.g., Huta \& Waterman, 2014), we included both in our analyses to assess the predictive power of pursuing virtue above and beyond hedonic motivation (see SOM-R for separate analyses with hedonic motivation). All 10 items were presented on a scale from 1 (strongly disagree) to 5 (strongly agree).

Wise Reasoning. Drawing from prior research on wise reasoning (Staudinger \& Glück, 2011; Grossmann et al., 2010; Grossmann \& Kross, 2014), we assessed participants' selfreported endorsement of wise reasoning using a 19-item scale (see Table S2 in SOM-R for items; adapted from Brienza, Kung, Santos, Bobocel, \& Grossmann, 2017). The scale was designed to assess distinctive subcomponents of wise reasoning across the psychological literature, as well as capture the overall cognitive framework of wise reasoning (Grossmann, 2017). Specifically, the scale measures five distinctive subcomponents of wise reasoning: i. considering others' perspectives (e.g., "making an effort to take the other person's perspective"); ii. intellectual humility (e.g., "considering whether others' opinions might be more correct than mine"); iii. search for compromise (e.g., "considering whether compromise is possible in resolving the situation"); iv. adopting an outsider's perspective (e.g., "trying to see the situation from the point of view of an uninvolved person"); and v. recognition of change (e.g., "considering how the situation might change through time"). For each item, participants reported on a scale from 1 
(very useless) to 5 (very useful), how valuable certain reasoning strategies would be if they were trying to resolve the conflict. To compute an overall measure of endorsement of wise reasoning, we averaged the 19 items together $(M=3.84, S D=.67, \alpha=.92)$. Additionally, we computed an average score for each individual subcomponent to explore the effect of conflict type within each dimension. Table S3 in the SOM-R presents the psychometric properties of the individual subcomponents across both presented studies. Table S4 in the SOM-R presents the loading results of a PCA factor analysis for the scale.

\section{Study 1 Results}

There was no gender effect and no Gender X Conflict Type interaction on the endorsement of wise reasoning strategies, $F s<1.00$. Consistent with prior research on Solomon's Paradox, there was a significant main effect of conflict type. Overall, participants endorsed wise reasoning strategies as more useful for resolving others' conflicts $(M=3.99, S D=$ $.61)$ than their own, $(M=3.70 ; S D=.69), F(1,264)=13.19, p<.001, \eta_{\mathrm{p}}{ }^{2}=.05,95 \% \mathrm{CI}=[.01$, $.11]$.

Pursuit of Virtue. To explore whether pursuit of virtue moderated conflict type, we first controlled for hedonic motivation. Consistent with prior theorizing that suggests pursuit of virtue and hedonic motivation are interrelated constructs (Huta \& Waterman, 2014), we found that the two were significantly correlated, $r=.42, p<.001$. We regressed pursuit of virtue on hedonic motivation, $\beta=.42(95 \% \mathrm{CI}=[.30, .57]), t(265)=7.52, p<.001$, and saved the unstandardized residuals as a measure of pursuit of virtue. There was a significant main effect of pursuit of virtue on the endorsement of wise reasoning strategies, $\beta=.23(95 \% \mathrm{CI}=[.11, .36]), t(264)=$ $3.77, p<.001$, revealing that those who endorsed a greater pursuit of virtue also endorsed wise reasoning strategies as more conducive for resolving social conflicts. More importantly, we 
found the predicted Pursuit of Virtue X Conflict Type interaction, $\beta=-.14$ (95\% CI = [-.24, $.03]), t(262)=-2.39, p=.018$. As depicted on the left panel of Figure 1, we did not find an effect of pursuit of virtue in the other-conflict condition, $\beta=.09(95 \% \mathrm{CI}=[-.04, .22]), t(262)=1.06, p$ $=.291$. However, participants in the self-conflict condition reported wise reasoning strategies as significantly more useful for resolving conflict as their pursuit of virtue increased, $\beta=.36(95 \%$ $\mathrm{CI}=[.20, .54]), t(262)=4.38, p<.001$. There was a significant difference across conflict types in the endorsement of wise reasoning strategies among participants who reported low (-1SD) pursuit of virtue, $\beta=.35(95 \% \mathrm{CI}=[.19, .50]), t(262)=4.30, p<.001$, but no differences emerged between conflict types for participants high (+1SD) in pursuit of virtue, $\beta=.08(95 \%$ $\mathrm{CI}=[-.07, .23]), t(262)<1, p=.365$.

To test whether the pursuit of virtue uniquely moderated the effect of conflict type on wise reasoning, above and beyond hedonic motivation, we reran these analyses with hedonic motivation as the moderating variable, controlling for pursuit of virtue. Hedonic motivation did not moderate the effect of conflict type, $\beta=-.01(95 \% \mathrm{CI}=[-.15, .12]), t(262)<1.00, p=.892$, suggesting that motivation for virtue, and not motivation in general, uniquely moderates Solomon's Paradox (see SOM-R for detailed analyses). 


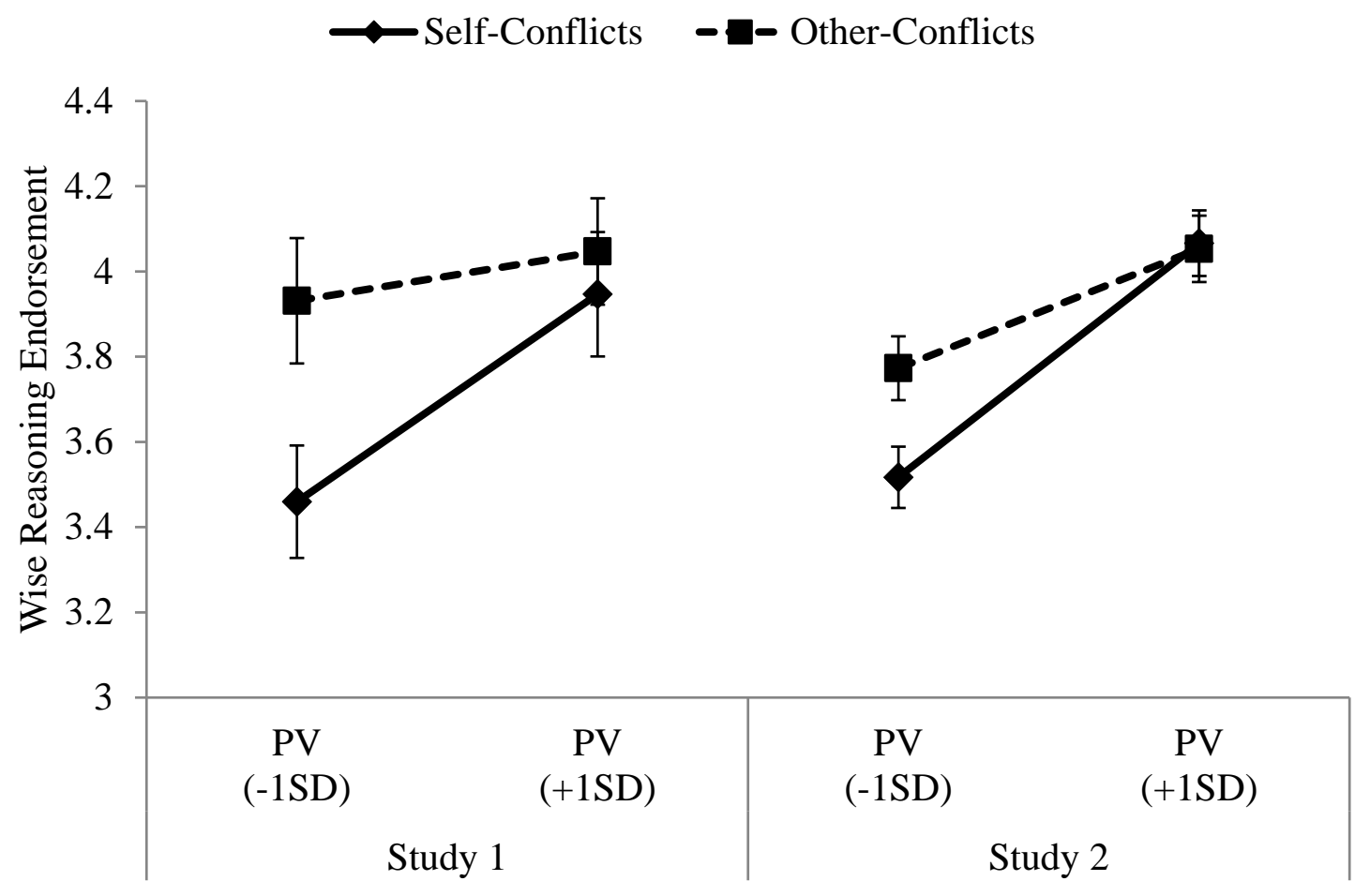

Figure 1. Endorsement of wise reasoning for self- and other-conflicts, across pursuit of virtue scores plotted at 1 standard deviation above and below the mean. PV = pursuit of virtue. PV scores represent the unstandardized residuals when regressing out hedonic motivation. Error bars represent the standard error of the mean.

Wise Reasoning Subcomponents. To disentangle which subcomponents of wise reasoning were most susceptible to Solomon's Paradox, and which components pursuit of virtue best predicted, we ran several follow up analyses with the individual subcomponents of our wise reasoning scale. Table 1 presents the means and effect sizes for each subcomponent across self and other-conflicts. The largest effect of the Solomon's Paradox was observed for the intellectual humility subcomponent. As shown in Table 2, pursuit of virtue significantly moderated two subcomponents: considering others' perspectives and intellectual humility. These results reveal that the effect of pursuing virtue on the endorsement of wise reasoning strategies was predominately driven by the recognition that one's own perspective and knowledge may be insufficient to help understand the aspects of a personal social conflict. 
Table 1

Wise Reasoning Subcomponents as a Function of Self-and Other Conflicts in Studies 1 and 2

\begin{tabular}{|c|c|c|c|c|c|c|c|c|}
\hline \multirow[b]{2}{*}{ Subcomponent } & \multicolumn{4}{|c|}{ Study 1} & \multicolumn{4}{|c|}{ Study 2} \\
\hline & Self & Other & $F$ & $\eta_{p}^{2}$ & Self & Other & $F$ & $\eta_{p}^{2}$ \\
\hline $\begin{array}{l}\text { 1. Considering others' } \\
\text { perspective }\end{array}$ & $3.81(.91)$ & $4.14(.81)$ & $9.63^{* *}$ & .04 & $3.90(.98)$ & $3.91(.96)$ & $<1.00$ & .0001 \\
\hline $\begin{array}{l}\text { 2. Intellectual } \\
\text { Humility }\end{array}$ & $3.52(.92)$ & $3.94(.73)$ & $16.42^{* * *}$ & .06 & $3.67(.98)$ & 3.79 (.99) & $4.90^{*}$ & .01 \\
\hline $\begin{array}{l}\text { 3. Search for } \\
\text { Compromise }\end{array}$ & $3.83(.91)$ & $4.11(.82)$ & $6.76^{*}$ & .03 & $3.95(.98)$ & $3.93(1.03)$ & $<1.00$ & .0001 \\
\hline $\begin{array}{l}\text { 4. Adopting an } \\
\text { Outsider's perspective }\end{array}$ & $3.56(1.01)$ & $3.64(1.03)$ & $<1.00$ & .001 & $3.43(1.18)$ & $3.56(1.16)$ & $6.02^{*}$ & .02 \\
\hline $\begin{array}{l}\text { 5. Recognition of } \\
\text { Change }\end{array}$ & $3.76(.75)$ & $4.05(.73)$ & $10.72^{* *}$ & .04 & $3.93(.88)$ & $3.98(.85)$ & 1.92 & .005 \\
\hline
\end{tabular}

\section{Study 2}

We pre-registered Study 2 to replicate and extend Study 1 results. Study 2 included measures of mood and self-esteem to further test whether virtue uniquely predicts the endorsement of wise reasoning strategies beyond related constructs. Additionally, Study 2 utilized a repeated measures design and investigated the effect of virtue on wise reasoning in a more age-heterogeneous sample.

\section{Method}

Sample. Utilizing the Pursuit of Virtue X Conflict Type interaction obtained in Study 1, our effect size was determined to be $\mathrm{f}^{2}=.117$. Based on this effect size, a suggested sample of 120 participants per condition was recommended by the G*Power program. Because a goal of our second study was to manipulate virtue using an additional two conditions, we decided to recruit a larger sample of roughly 400 participants to account for our exclusionary criteria and 
effect size. We recruited 393 American participants from a crowdsourcing website with a diverse population (Paolacci \& Chandler, 2014) and each participant was compensated 0.75 USD for their participation. Following our pre-registered exclusionary criteria to assess participant's attention, we excluded participants who failed attention check questions and spent fewer than seven minutes to complete our study. Our final sample consisted of 356 participants (218 females; mean age $=37.62$ years, $S D=12.89)$.

Procedure and Materials. Participants were recruited online to participate in a study on motivation, meaning, and relationships. Upon providing consent, participants reported on their pursuit of virtue motivation and several additional exploratory measures (e.g., emotional intelligence). In an attempt to manipulate virtuous motivations, participants were then randomly assigned to one of two value affirmation conditions (see SOM-R for further details on this manipulation and details on all additional measures). The value affirmation manipulation did not predict our subsequent measures of endorsement of wise reasoning, self-esteem, or positive and negative affect $(F \mathrm{~s}<1.00)$. The affirmation manipulation did not significantly interact with our primary findings, and subsequent results did not differ with and without its inclusion in our models. Thus, we do not discuss it further here and report results without its inclusion in our models.

Upon completing the affirmation manipulation, participants were prompted to report on a social conflict they were involved in (self-conflict), and a conflict that a friend was involved in (other-conflict). The instructions for each were identical to that of Study 1. For self-conflicts, $21.9 \%$ of participants reported that their conflict was with romantic partner, $34.6 \%$ with family members, $36.2 \%$ with friends, and $7.3 \%$ were unspecified or ambiguous (e.g., participants listed a name). For other-conflicts, $16.9 \%$ reported that their friend's conflicts were with a romantic 
partner, $27.2 \%$ with family members, $44.7 \%$ with other friends, and $11.2 \%$ were unspecified or ambiguous. All participants first reported a self-conflict, and then an other-conflict. After each type of conflict, participants reported their endorsement of wise reasoning strategies to resolve the conflict, followed by a question on how important the conflict felt to them on a scale from 1 (not at all) to 5 (very important). Participants then completed a measure of self-esteem and their present mood.

Pursuit of Virtue. As with Study 1, participants completed a state modified version of the HEMA, including five statements assessing their pursuit of virtue $(M=4.18 ; S D=.70, \alpha=.88)$ and five statements assessing their hedonic motivation $(M=4.07 ; S D=.72, \alpha=.87)$.

Wise Reasoning. Identical to the procedures from Study 1, participants reported on a 19item scale assessing how valuable certain reasoning strategies would be if they were trying to resolve the conflicts they reported. An overall average score of wise reasoning scores was computed for both self-conflicts $(\alpha=.94)$ and other-conflicts $(\alpha=.96)$. Endorsement of wise reasoning strategies for self and other-conflicts were highly correlated, $r=.65, p<.001$. As with Study 1, we also computed a score for each of the five subcomponents, separately for participant's reports of self and other-conflicts. Table S2 displays the psychometric properties of the scale, suggesting that the respective subcomponents hung together well within each type of conflict.

Self-esteem and Mood. To test whether virtue uniquely predicted the endorsement of wise reasoning strategies beyond its related constructs, we included measures of mood and selfesteem. These constructs are considered closely related to virtue (Ryan, Huta, \& Deci, 2013). Participants completed the 10-item Rosenberg self-esteem scale (Rosenberg, 1965), which consisted of items assessing participant's evaluations of the self (e.g., As a whole, I am satisfied 
with myself) on a scale from 1 (strongly disagree) to 5 (strongly disagree). The items hung together well $(M=3.84, S D=.84, \alpha=.92)$ and thus a mean score for self-esteem was computed by averaging the items together.

To assess participant's state affect, they completed the 20-item Positive and Negative Affect Scale (PANAS; Watson, Clark, \& Tellegen, 1988). Participants reported on a scale from 1 (strongly disagree) to 5 (strongly agree), how they currently felt on ten positive affect items (e.g., excited, enthusiastic, proud; $M=3.26, S D=.80, \alpha=.89$ ) and ten negative affect items (e.g., upset, irritable, hostile; $M=1.93 S D=.81, \alpha=.91)$. An average score was computed separately for positive and negative affect.

\section{Study 2 Results}

A repeated measures ANOVA, where conflict type served as the repeated measures variable, revealed that participants own conflicts felt more important to them $(M=3.83 ; S D=$ 1.12) than others' conflicts $(M=3.70 ; S D=1.08), F(1,354)=4.32, p=.038, \eta_{\mathrm{p}}{ }^{2}=.01,95 \% \mathrm{CI}$ $=[.0001, .05]$. Importance of the conflict did not interact with pursuit of virtue to predict the endorsement of wise reasoning, $F(1,354)<1.00, p=.442$. A main effect of gender emerged, suggesting that females endorsed wise reasoning strategies, across both self and other-conflicts

as more useful than males, $F(1,351)=4.76, p=.030, \eta_{\mathrm{p}}^{2}=.01,95 \% \mathrm{CI}=[.0001, .05]$. We were not predicting this effect and do not discuss it further here, but further results involving gender are presented in the SOM-R. Converging with results from Study 1 and prior research on Solomon's Paradox, we found a marginal effect of conflict type on the endorsement of wise reasoning, $F(1,353)=2.74, p=.099, \eta_{\mathrm{p}}^{2}=.01,95 \% \mathrm{CI}=[.0001, .04]$. Participants endorsed wise reasoning as more conducive to resolving others' conflicts $(M=3.85, S D=.84)$ than their own conflicts $(M=3.79, S D=.81)$. As shown in Table 1 , greater intellectual humility and 
greater adoption of others' perspectives in the other-conflict condition drove these overall results.

Pursuit of Virtue. Following procedures outlined in Study 1, we examined whether pursuit of virtue moderated conflict type by first controlling for hedonic motivation. Pursuit of virtue and hedonic motivation were significantly correlated, $r=.41, p<.001$. We regressed pursuit of virtue on hedonic motivation, $\beta=.41(95 \% \mathrm{CI}=[.28, .60]), t(353)=8.53, p<.001$, and saved the unstandardized residuals as a measure of pursuit of virtue. There was a significant main effect of pursuit of virtue on the endorsement of wise reasoning strategies, averaged across both self and other-conflicts, $F(1,353)=41.07, p<.001, \eta_{\mathrm{p}}^{2}=.10,95 \% \mathrm{CI}=[.05, .17]$, suggesting that those who endorsed greater pursuit of virtue tended to see wise reasoning as more useful in resolving social conflicts. Replicating results from Study 1, we found a significant Pursuit of Virtue X Conflict Type interaction, $F(1,353)=4.61, p=.032, \eta_{\mathrm{p}}^{2}=.01,95 \% \mathrm{CI}=$ $[.0001, .05]$. As depicted on the right panel of Figure 1, pursuit of virtue significantly predicted greater endorsement of wise reasoning strategies for other-conflicts, $F(1,353)=22.64, p<.001$, $\eta_{\mathrm{p}}^{2}=.02,95 \% \mathrm{CI}=[.02, .11]$, and self-conflicts, $F(1,353)=46.29, p<.001, \eta_{\mathrm{p}}{ }^{2}=.12,95 \% \mathrm{CI}=$ $[.06, .18]$. Participants high in pursuit of virtue (+1SD), showed no difference in their endorsement of wise reasoning strategies across self- and other-conflicts, $F(1,353)<1, p=.900$, whereas a significant difference emerged for those low in pursuit of virtue (-1SD). These participants reported a greater endorsement of wise reasoning strategies for resolving others' conflicts than their own, $F(1,353)=6.09, p=.014, \eta_{\mathrm{p}}{ }^{2}=.02,95 \% \mathrm{CI}=[.006, .05]$.

Following Study 1, we reran these analyses with hedonic motivation as the moderating variable, controlling for pursuit of virtue. Hedonic motivation did not moderate the effect of conflict type, $F(1,353)<1, p=.356$, suggesting that motivation for virtue, and not motivation in 
general, uniquely moderates Solomon's Paradox (see SOM-R for detailed analyses).

Self-esteem and Mood. Positive affect was significantly and positively related to pursuit of virtue, $r=.25, p<.001$. Positive affect also significantly predicted the endorsement of wise reasoning strategies, $F(1,353)=14.77, p<.001, \eta_{\mathrm{p}}^{2}=.04,95 \% \mathrm{CI}=[.009, .09]$. Greater positive affect was associated with greater endorsement of wise reasoning, both for self-conflicts, $\beta=.18$ $(95 \% \mathrm{CI}=[.04, .13]), t(353)=3.49, p=.001$, and other-conflicts, $\beta=.18(95 \% \mathrm{CI}=[.05, .32])$, $t(353)=3.46, p=.001$. Negative affect and self-esteem were not significantly related to pursuit of virtue, $|r s|<.08, p s>.147$, and neither predicted the endorsement of wise reasoning strategies, $F s<1, p>.252$. Neither positive affect, negative affect, nor self-esteem interacted with conflict type to predict the endorsement of wise reasoning strategies, $F s<1.31$, ps $>.252$. Additionally, they did not significantly moderate the Pursuit of Virtue X Conflict Type interaction, $F \mathrm{~s}<2.25, p s>.107$.

Wise Reasoning Subcomponents. As shown in Table 1, follow up analyses with the individual subcomponents of wise reasoning revealed that the main effect of conflict type was strongest for the intellectual humility and adopting an outsider's perspective subcomponents of wise reasoning. The effect of conflict type on the endorsement of wise reasoning strategies was not present for other subcomponents. Additionally, Table 2 presents the moderation of pursuit of virtue on conflict type for each of the subcomponents in Study 2. There was a significant moderation of pursuit of virtue on the search for compromise and the intellectual humility subcomponents.

Table 2 Model Effects for the Five Wise Reasoning Subcomponents in Studies 1 and 2

\begin{tabular}{lcccc}
\hline Variable & $\beta$ & $T$ & $p$-value & 95\% CI \\
\hline \multicolumn{4}{c}{ Considering Others' Perspectives } \\
$\quad$ Study 1: \\
$\quad$ Conflict Type & .18 & 3.17 & .002 & $.07, .30$
\end{tabular}


Pursuit of Virtue

Condition X Pursuit of Virtue

$$
\begin{array}{rrrr}
.40 & 4.88 & <.001 & .24, .57 \\
-.34 & -4.10 & <.001 & -.50,-.19
\end{array}
$$

Study 2:

Conflict Type

$\begin{array}{rrrr}.01< & <.00 \quad .821 \quad-.09, .11\end{array}$

Pursuit of Virtue

$\begin{array}{llll}.26 & 5.05 & <.001 & .16, .36\end{array}$

Condition X Pursuit of Virtue

$-.07$

$-1.33$

$.185 \quad-.17, .03$

\section{Intellectual Humility}

\section{Study 1:}

Conflict Type

.24

Pursuit of Virtue

.27

$4.07<.001$

$.12, .35$

Condition X Pursuit of Virtue

$-.20$

3.27

.001

.04. .47

Study 2:

Conflict Type

.12

$-2.34$

.020

$-.37,-.001$

Pursuit of Virtue

.21

2.22

.027

$.01, .22$

Condition X Pursuit of Virtue

$-.11$

$4.10<.001$

$.11, .32$

Search for Compromise

Study 1:

Conflict Type

.16

$-2.10$

.037

$-.21,-.01$

Pursuit of Virtue

.25

2.58

.010

$.04, .27$

Condition X Pursuit of Virtue

$-.13$

2.89

.005

$.04, .45$

Study 2:

Conflict Type

Pursuit of Virtue

$\begin{array}{rrrr}-.01<1.00 \quad & .792 \quad-.11, .08\end{array}$

.19

3.62

$.09, .30$

Condition X Pursuit of Virtue

$-.12$

$-2.37$

$<.001$

$-.21,-.02$

\section{Adopting an Outsider's Perspective}

Study 1:

Conflict Type

Pursuit of Virtue

$$
.03
$$

.21

$<1.00$

.588

$-.08, .15$

Condition X Pursuit of Virtue

.02

2.49

.013

$.05, .40$

Study 2:

Conflict Type

Pursuit of Virtue

.11

$<1.00$

.784

$-.16, .18$

Condition X Pursuit of Virtue

.18

2.46

.015

$.02, .20$

.05

3.44

.001

$.08, .28$

1.09

.278

$-.04, .14$

Recognition of Change

\section{Study 1:}

Conflict Type .19

.26

3.27

.001

$.08, .31$

Pursuit of Virtue

$-.11$

3.00

.003

$.07, .42$

Condition X Pursuit of Virtue

$-1.24$

.216

$-.26, .08$

Study 2:

Conflict Type

.07

Pursuit of Virtue

.20

1.39

.166

$-.02, .16$

Condition X Pursuit of Virtue

$-.09$

$4.00<.001$

$.10, .31$

$-1.95$

$.052-.19, .0001$

Note. Conflict type was dummy coded in Study 1 ( $0=$ self-conflicts; $1=$ other-conflicts $)$ in Study 1 and effects coded in Study 2 (-1 = self-conflicts; 1 = other-conflicts), such that positive beta coefficients reflect greater wise reasoning for others' conflicts. 


\section{Discussion}

The present studies are the first to our knowledge that empirically links the psychological construct of virtue with wisdom. Consistent with past research on Solomon's Paradox, our results indicate that individuals endorse wise reasoning strategies as more useful for resolving others' social conflicts than their own. However, our work advances this prior finding in two ways. First, we find that those who endorse the pursuit of virtue endorse wise reasoning strategies as equally useful for themselves as they do for others. Secondly, we find evidence that pursuing virtue may be most beneficial to specific subcomponents of wise reasoning when attempting to resolve personal conflicts.

Although wisdom is operationalized as a multidimensional construct, it is often treated as a singular construct (e.g., Grossmann et al., 2010). Across two studies, assessing the individual subcomponents of wise reasoning allowed us to disentangle the relationship between wisdom and virtue. While the moderation of virtue emerged for several subcomponents across both studies, pursuing virtue influenced participants' endorsement of wise reasoning overall by specifically increasing the value of intellectual humility-i.e., recognizing that their perspective alone may be insufficient to understand their social conflict. This finding is consistent with prior research on virtue, which suggests that virtue as a mode of self-transcendence allows people to see through the "illusions of one's truth" (Le, 2011).

The present study opens up avenues for future studies to pursue ways to enhance wisdom. While past researchers have endeavored to do so (e.g., Kross \& Grossmann, 2012), they have predominately relied on situation-dependent self-distancing techniques that may feel unconventional for certain groups (e.g., different cultural groups; Grossmann \& Kross, 2010). The pursuit of virtue may have wider implications than self-distancing because it involves a person's broader goals and motivation. Although we acknowledge that the correlational nature of 
our design should not be used to argue that virtuous motives foster wise reasoning, our research suggests that virtue may still be a unique and fruitful tool for future researchers seeking ways to enhance wisdom.

Author Contributions: A. C. Huynh, H. Oakes, and I. McGregor contributed to the research concept, designed the studies, and interpreted the findings. A. C. Huynh performed the data analysis and drafted the manuscript. H. Oakes and I. McGregor provided revisions to the drafts. G. Shay organized the data and assisted with drafting the manuscript. All authors approved the final version of the manuscript for submission. 


\section{References}

Aquinas, T. (n.d./2012). Summa Theologica. Authentic Media Inc.

Baltes, P. B., \& Smith, J. (2008). The fascination of wisdom: Its nature, ontogeny, and function. Perspectives on Psychological Science, 3, 56-64. http://doi.org/10.1111/j.17456916.2008.00062.x

Baltes, P. B., \& Staudinger, U. M. (2000). Wisdom: a metaheuristic (pragmatic) to orchestrate mind and virtue toward excellence. American Psychologist, 55, 122-136.

Bauer, J. J., McAdams, D. P., \& Pals, J. L. (2008). Narrative identity and eudaimonic wellbeing. Journal of Happiness Studies, 9, 81-104.

Brienza, J., Kung, F. Y. H., Santos, H. C., Bobocel, D. R., \& Grossmann, I. (2017, June 1). Wisdom, bias, and balance: Toward a process-sensitive measurement of wisdom-related cognition. Retrieved from osf.io/preprints/psyarxiv/p25c2

Dambrun, M., \& Ricard, M. (2011). Self-centeredness and selflessness: A theory of self-based psychological functioning and its consequences for happiness. Review of General Psychology, 15, 138-157.

Deci, E. L., \& Ryan, R. M. (2008). Hedonia, eudaimonia, and well-being: An introduction. Journal of Happiness Studies, 9, 1-11.

Delany, J. (1911). Prudence. The Catholic Encyclopedia. New York: Robert Appleton Company. Retrieved from http://www.newadvent.org/cathen/12517b.htm

Grossmann, I. (2017). Wisdom in context. Perspectives on Psychological Science, 12, $233-$ 257.

Grossmann, I. \& Kross, E. (2010). The impact of culture on adaptive vs. maladaptive selfreflection. Psychological Science, 21, 1150-1157. 
Grossmann, I. \& Kross, E. (2014). Exploring “Solomon’s paradox”: Self-distancing eliminates the self-other asymmetry in wise reasoning about close relations in younger and older adults. Psychological Science, 25, 1571-1580.

Grossmann, I., Na, J., Varnum, M. E. W., Kitayama, S., \& Nisbett, R. E. (2013). A Route to Well-being: Intelligence vs. Wise Reasoning. Journal of Experimental Psychology: General, 142, 944-953.

Grossmann, I., Na, J., Varnum, M. E., Park, D. C., Kitayama, S., \& Nisbett, R. E. (2010). Reasoning about social conflicts improves into old age. Proceedings of the National Academy of Sciences, 107, 7246-7250.

Huta, V., \& Ryan, R. M. (2010). Pursuing pleasure or virtue: The differential and overlapping well-being benefits of hedonic and eudaimonic motives. Journal of Happiness Studies, 11, 735-762.

Huta, V., \& Waterman, A. S. (2014). Eudaimonia and its distinction from hedonia: Developing a classification and terminology for understanding conceptual and operational definitions. Journal of Happiness Studies, 15, 1425-1456.

Kraut, R. (2016). Aristotle's ethics. In E. N. Zalta (Ed.), The Stanford Encyclopedia of Philosophy. Retrieved from http://plato.stanford.edu/archives/spr2016/entries/aristotleethics/

Kross, E., \& Grossmann, I. (2012). Boosting wisdom: distance from the self enhances wise reasoning, attitudes, and behavior. Journal of Experimental Psychology: General, 141, 43-48.

Kunzmann, U. \& Baltes, P. B. (2003). Wisdom-related knowledge: Affective, motivational, and interpersonal correlates. Personality and Social Psychology Bulletin, 29, 1104-1119. 
Le, T. N. (2011). Life satisfaction, openness value, self-transcendence, and wisdom. Journal of Happiness Studies, 12, 171-182.

Levenson, M. R., Jennings, P. A., Aldwin, C. M., \& Shiraishi, R. W. (2005). Self-transcendence: Conceptualization and measurement. The International Journal of Aging and Human Development, 60, 127-143.

McGregor, I., Zanna, M. P., Holmes, J. G., \& Spencer, S. J. (2001). Compensatory conviction in the face of personal uncertainty: going to extremes and being oneself. Journal of Personality and Social Psychology, 80, 472-488.

Mickler, C., \& Staudinger, U. M. (2008). Personal wisdom: validation and age-related differences of a performance measure. Psychology and Aging, 23, 787-799.

Paolacci, G., \& Chandler, J. (2014). Inside the Turk: Understanding Mechanical Turk as a participant pool. Current Directions in Psychological Science, 23, 184-188.

Pronin, E., Olivola, C. Y., \& Kennedy, K. A. (2008). Doing unto future selves as you would do unto others: Psychological distance and decision making. Personality and Social Psychology Bulletin, 34, 224-236.

Rosenberg, M. (1965). Society and the adolescent self-image (Vol. 11, p. 326). Princeton, NJ: Princeton university press.

Ryan, R. M., Huta, V., \& Deci, E. L. (2013). Living well: A self-determination theory perspective on eudaimonia. In The exploration of happiness (pp. 117-139). Springer Netherlands.

Staudinger, U. M., \& Glück, J. (2011). Psychological wisdom research: Commonalities and differences in a growing field. Annual Review of Psychology, 62, 215-241.

Watson, D., Clark, L. A., \& Tellegen, A. (1988). Development and validation of brief measures 
of positive and negative affect: the PANAS scales. Journal of Personality and Social Psychology, 54, 1063-1070. 
** All data, materials, and study pre-registrations reported for this manuscript are publicly available online and can be accessed at https://osf.io/4chuy/

\section{Supplementary Online Materials - Reviewed (SOM-R):}

The Wisdom in Virtue: Motivation for Virtue Predicts Wise Reasoning about Personal

\section{Conflicts}

Alex C. Huynh, Harrison Oakes, Garrett Shay \& Ian McGregor

University of Waterloo

\section{Content:}

\section{Supplementary Methods and Results:}

- Information on Study $1 \& 2$ procedures w/ additional measures used in both studies.

- Includes analyses exploring the "mind-in-eyes" test predicting wise reasoning.

- Study $1 \& 2$ analyses of hedonic motivation and pursuit of virtue predicting wise reasoning.

\section{Supplementary Figures and Tables:}

- Figure S1: Mind-in-eyes test predicting wise reasoning in Study 1.

- Table S1: Descriptives and zero-order correlations between measures of interest.

- Table S2: 19-item wise reasoning scale broken down by its subcomponents.

- Table S3: Psychometric properties and the subcomponents of the wise reasoning scale.

- Table S4: Exploratory Factor Analysis - wise reasoning Scale 


\section{Supplementary Methods and Results}

\section{Study 1 additional measures of interest}

1. Personal need for structure (Thompson et al., 2001)

2. Preference for consistency (Cialdini et al., 1995)

3. Meaning-in-life (Steger et al., 2006)

4. Felt uncertainty (McGregor et al., 2001)

5. Mind-in-eyes test (Baron-Cohen et al., 2001)

\section{Study 1 Procedure and Results}

As described in the main text, the present study took place during a larger study on motivation and meaning seeking. At the start of the study, participants first completed a 12-item scale assessing their personal need for structure (e.g., "I don't like situations that are uncertain"; $\alpha=.75$, Thompson, Naccarato, Parker, \& Moskowitz, 2001) and a 9-item preference for consistency scale (e.g., "I typically prefer to do things the same way"; $\alpha=.83$, Cialdini, Trost, \& Newsom, 1995). Participants rated their agreement with items on both scales from 1 (strongly disagree) to 5 (strongly agree). An overall mean was calculated for both scales. Neither personal need for structure nor preference for consistency were significantly related to the pursuit of virtue, or overall wise reasoning, $t s<1.54$. Following these scales, participants then completed a social intelligence exercise (i.e., mind-in-eyes test; Baron-Cohen et al., 2001). We report the results of this test in the subsequent section (see below).

Following these measures, participants were assigned to one of three additional motivational conditions: a) approach $(n=86), \mathrm{b})$ avoidance $(n=89)$, or $\mathrm{c})$ a control condition in which motivation was not manipulated $(n=92)$. Participants were prompted with the following instructions and spent 2 minutes writing their thoughts down following each prompt:

Approach: Is there something you desire so eagerly that you get excited when you even imagine it? It might be something specific, like a relationship partner, career, 'A' grade, party, vacation, or any other desirable event; or it might be something more general that inspires or empowers you when you imagine it, such as 
acceptance, self-respect, freedom, kindness, compassion, peace, beauty, or social justice.

Avoidance: Is there something you want to avoid so badly that you get anxious when you even imagine it? It might be something specific, like a relationship dispute, a career outcome, a bad grade, sickness, an obligation, or any other undesirable event; or it might be something more general that repulses or depresses you when you imagine it, such as rejection, losing self-respect, getting stuck, cruelty, hostility, conflict, ugliness, or exploitation.

Control: Let your mind wander. As you do this, record any thoughts that pass through your mind, in the space below. Feel free to be as brief or descriptive as you like.

As this manipulation was part of a separate line of research involving the relationship between motivation states and preferences for consistency and structure, we held no a priori hypotheses about how it might relate to the measures relevant to the current study. Nevertheless, we tested whether this manipulation influenced our results. The motivational manipulation did not significantly predict the pursuit of virtue, or overall wise reasoning, $F s<1.27$. Moreover, it did not interact with our conflict type manipulation in predicting the endorsement of wise reasoning, $F(2,260)=1.81, p=.165$. Nonetheless, we included the manipulation as a covariate in all of our analyses and found that it did not impact the results in our supplemental materials or main text. As such, we report results in both without it included in the model.

Prior to completing our conflict type manipulation, and after completing the pursuit of virtue and mind-in-eyes test, participants also completed a 10-item meaning in life questionnaire (Steger, Frazier, Oishi, \& Kaler, 2006), involving a 5-item subcomponent assessing presence of meaning (e.g., "I understand my life's meaning"; $\alpha=.89$ ) and a 5-item subcomponent assessing search for meaning (e.g., "I am always looking to find my life's purpose"; $\alpha=.88$ ). This measure was followed by a 19-item felt uncertainty scale (e.g., "I feel uneasy"; $\alpha=.94$, McGregor, Zanna, Holmes, \& Spencer, 2001). Participants rated their agreement with items for felt 
uncertainty and meaning in life from 1 (strongly disagree) to 5 (strongly agree). Felt uncertainty and presence of meaning did not significantly predict the endorsement of wise reasoning, $t s<$ 1.43, nor did they moderate the effect of conflict type in predicting the endorsement of wise reasoning, $t s<1.00$. Search for meaning significantly predicted the endorsement of wise reasoning, $\beta=.19(95 \% \mathrm{CI}=[.04, .34]), t(263)=3.11, p=.002$. The higher participants' search for meaning score, the more they reported wise reasoning strategies as useful in resolving their conflicts. However, search for meaning did not moderate the effect of conflict type on wise reasoning, $\beta=-.02(95 \% \mathrm{CI}=[-.16, .14]), t(263)<1.00, p=.740$.

Mind-in-Eyes Test. Our initial interest in these studies stemmed from exploring the relationship between social intelligence and wise reasoning. Accordingly, participants completed a mind-in-eyes (MIE) test as a measure of social intelligence (see also social sensitivity, BaronCohen et al., 2001), prior to reporting on their social conflict and wise reasoning. In this task, participants were presented with images of human facial expressions that are limited to the eyes and a small area around the eyes. For each image, participants were presented with four emotional or mental states (e.g., playful, comforting, irritated, bored) and asked to "choose which word best describes what the person in the picture is thinking or feeling”. Each image has one correct answer with three foils varying in their similarity to the correct answer. Participants evaluated 36 pairs of eyes and we computed the proportion of correct responses. The distribution of performance accuracy in our sample $(M=.68, S D=.11)$ was similar to prior adult samples (e.g., Baron-Cohen et al., 2001). Pursuit of virtue did not correlate with MIE scores, $r=.003, p=$ .964, and a Pursuit of Virtue X MIE X Conflict Type interaction predicting the endorsement of wise reasoning was not significant, $\beta=-.02 t(258)<1.00, p=.811$. 
There was no effect of MIE on the endorsement of wise reasoning, $\beta=-.005, t(261)<$ $1.00, p=.929$. However, a significant interaction between SI and conflict type emerged, $\beta=.21$ $(95 \% \mathrm{CI}=[.08, .34]), t(261)=3.49, p=.001$. As shown in Figure S1, as performance on the MIE task improved, participants expressed greater self-other asymmetry in their endorsement of wise reasoning strategies. Participants in the self-conflict condition reported wise reasoning strategies as less useful in resolving their conflict as their performance on the MIE task improved, $\beta=-.22(95 \% \mathrm{CI}=[-.42,-.04]), t(261)=-2.57, p=.011$, whereas those in the otherconflict condition reported wise reasoning strategies as more useful as their MIE task performance improved, $\beta=.19(95 \% \mathrm{CI}=[.02, .38]), t(261)=2.34, p=.020$. Among participants who performed relatively poorly (-1SD) on the MIE task, no differences on their endorsement of wise reasoning emerged between conflict types, $\beta=.02(95 \% \mathrm{CI}=[-.16, .18])$, $t(261)<1.00, p=.843$. However, among participants who performed relatively well (+1SD) on the MIE task, those in the other-conflict condition reported wise reasoning strategies as more useful than those in the self-conflict condition, $\beta=.43(95 \% \mathrm{CI}=[.25, .60]), t(261)=5.10, p<$ .001 .

\section{Study 2 additional measures of interest}

1. Meaning-in-life (Steger et al., 2006)

2. Trait Emotional Intelligence (adapted from Schutte et al., 1998)

3. PANAS (Watson et al., 1988)

4. Self-esteem (Rosenberg, 1956)

5. Mind-in-eyes test (Baron-cohen et al., 2001)

\section{Study 2 Procedure and Results}

As described in the main text, results of interactions and main effects involving conflict type (self- vs. other-conflicts) were assessed using a repeated measures ANOVA. This study was 
advertised online as a study on motivation, meaning, and relationships. Participants began the study by completing Steger's meaning-in-life questionnaire. We computed an average score for each of the 5-item subcomponents (presence of meaning: $\alpha=.92$; search for meaning: $\alpha=.94$ ). Both subcomponents significantly predicted the endorsement of wise reasoning, such that greater presence of and search for meaning were associated with a greater endorsement of wise reasoning strategies (presence of meaning: $F(1,350)=10.54, p=.001$; search for meaning: $F(1$, $350)=6.96, p=.010)$. Zero-order correlations between these and wise reasoning scores are presented in Table S1. Neither scale significantly interacted with our conflict type manipulation (self- vs. other-conflict) to predict the endorsement of wise reasoning, $F \mathrm{~s}<1.00, p \mathrm{~s}>.328$. Following these scales, participants completed the pursuit of virtue and pursuit of hedonia scales, followed by the mind-in-eyes task. Participants then completed a 12-item trait emotional intelligence scale (modified from Schutte et al., 1998). These items contained questions to get at participants' recognition of their own and others' emotions (e.g., I have control over my emotions; I know what other people are feeling just by looking at them; $\alpha=.80)$. The mind-ineyes and emotional intelligence scale results are presented in their own section (below). To reduce any effect the completion of these scales might have had on our manipulation, participants then completed a word completion filler task where they wrote the first word that came to mind for five incomplete words (e.g., $\mathrm{k}_{--} \mathrm{s}$ ).

As described in the main text, a goal of this study was to try and manipulate virtuous motives by asking participants to reflect on their values. Thus, we randomly assigned participants to either write about their most important value, or their least important value that might, nonetheless, be important to someone else. Using previous paradigms of manipulating self-affirmation (Sherman, Nelson, and Steele, 2000), participants were prompted with the 
following instructions after considering the following six values: Arts, Business, Helping Others, Relationships, Religion, and Science

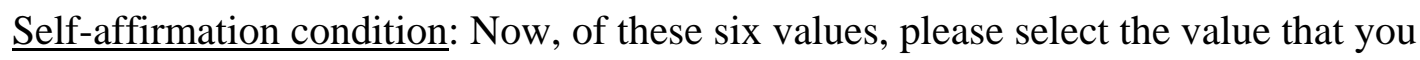
personally find to be the most important and take a moment to write about why this value is important to you.

Control: Now, of these six values, please select the value that you personally find to be the least important and take a moment to write about why this value might be important to someone else.

Upon completing this task, participants were instructed to report on two social conflicts as outlined in the main text. This value affirmation manipulation did not significantly predict the endorsement of wise reasoning strategies for either self-conflicts, $F<1.00, p=.586$, or otherconflicts, $F<1.00, p=.489$. The manipulation also did not interact with pursuit of virtue to predict overall wise reasoning, $F<1.00, p=.902$. Because the manipulation did not work the way we had hypothesized, we included it in the model when performing the analyses presented in the main text. None of the significant results reported in the main text differed as a function of including (or not) this manipulation as a covariate in our model. As such, we do not include this manipulation in the model for our results reported in the main text. Following the completion of the conflict type manipulation and wise reasoning scale, participants next rated their current affect (e.g., PANAS) and completed the Rosenberg self-esteem scale (Rosenberg, 1956). Finally, we collected participants' demographic information and fully debriefed them.

Mind-in-Eyes Test and Emotional Intelligence Scale. In an effort to replicate Study 1's moderation of social intelligence performance, participants completed the same mind-in-eyes (MIE) task described in Study 1. The distribution of performance accuracy on the MIE task was 
similar to that observed in Study $1(M=.68, S D=.17)$. Participants also completed a measure of emotional intelligence, which has previously been defined as a component of social intelligence (Salovey \& Mayer, 1990). The emotional intelligence measure was significantly correlated with MIE performance, $r=.183, p=.001$. While the MIE task was not significantly related to overall wise reasoning, $F(1,353)<1.00, p=.630$, the emotional intelligence measure was, $F(1,353)=$ $33.86, p<.001, \eta_{\mathrm{p}}^{2}=.09,95 \% \mathrm{CI}=[.04, .15]$, suggesting that as scores on emotional intelligence increased, so did the endorsement of wise reasoning strategies. MIE was not significantly correlated with pursuit of virtue, $r=.027, p=.609$, but emotional intelligence was, $r=.213, p<.001$. The Conflict Type X MIE interaction pattern observed in Study 1 was not found in Study 2, $F(1,353)<1.00, p=.630$. The Conflict Type X Emotional Intelligence interaction was also not significant, $F(1,353)<1.00, p=.358$.

Study 1 Hedonic Motivation Predicting Wise Reasoning. As part of our test of whether the pursuit of virtue moderated Solomon's Paradox above and beyond the pursuit of hedonia, we also tested whether pursuit of hedonia moderated Solomon's Paradox. We first controlled for pursuit of virtue by regressing mean hedonia scores on pursuit of virtue scores $\beta=$ $.42(95 \% \mathrm{CI}=[.30, .57]), t(265)=7.52, p<.001$, and saved the unstandardized residuals as a measure of pursuit of hedonia. When we entered these residuals into our model, a trending main effect of hedonic pursuit predicting the endorsement of wise reasoning strategies emerged, $\beta=$ $.09(95 \% \mathrm{CI}=[-.04, .26]), t(263)=1.72, p=.078$, suggesting that the endorsement of wise reasoning may increase slightly as the endorsement of hedonic pursuit increases. Hedonic pursuit did not moderate the effect of conflict type on the endorsement of wise reasoning, $\beta=-.01$ (95\% $\mathrm{CI}=[-.12, .09]) t(261)<1, p=.868$. Similarly, hedonic pursuit did not moderate conflict type in any subsequent analyses on the five subcomponents of wise reasoning, $t s<1.04$. 
Study 2 Hedonic Motivation Predicting Wise Reasoning. Following procedures outlined for Study 1 (above), we also sought to test whether pursuit of hedonia moderated Solomon's Paradox in Study 2. We first controlled for pursuit of virtue by regressing mean hedonia scores on pursuit of virtue scores $\beta=.41(95 \% \mathrm{CI}=[.30, .53]), t(353)=8.53, p<.001$, and saved the unstandardized residuals as a measure of the pursuit of hedonia. As with Study 1, a trending main effect of hedonic pursuit predicting the endorsement of wise reasoning emerged, $F(1,353)=2.54, p=.112$, suggesting that the endorsement of wise reasoning increases slightly as the endorsement of hedonic pursuit also increases. However, consistent with Study 1, the pursuit of hedonia did not significantly moderate the effect of conflict type on wise reasoning, $F(1,353)<1, p=.356$. Hedonic pursuit also did not moderate conflict type in any subsequent analyses on the five subcomponents of wise reasoning, $F s<1.81$.

Study 2 Gender Effects on Wise Reasoning. There was a significant main effect of gender on the endorsement of wise reasoning strategies, $F(1,351)=4.76, p=.030, \eta_{\mathrm{p}}{ }^{2}=.01$, $95 \% \mathrm{CI}=[.0001, .05]$, suggesting that females perceived wise reasoning as slightly more useful than males. There was no effect of gender on the endorsement of wise reasoning for selfconflicts $F(1,351)=1.39, p=.239$, but a significant effect emerged for other-conflicts $F(1,351)$ $=7.77, p=.006, \eta_{\mathrm{p}}{ }^{2}=.02,95 \% \mathrm{CI}=[.001, .06]$. Females perceived wise reasoning as more useful for resolving others' conflicts $(M=3.95, S D=.74)$ than males $\operatorname{did}(M=3.69, S D=.97)$. The Gender X Conflict Type interaction was marginal, $F(1,351)=3.59, p=.059$. 


\section{Supplementary Figures and Tables}

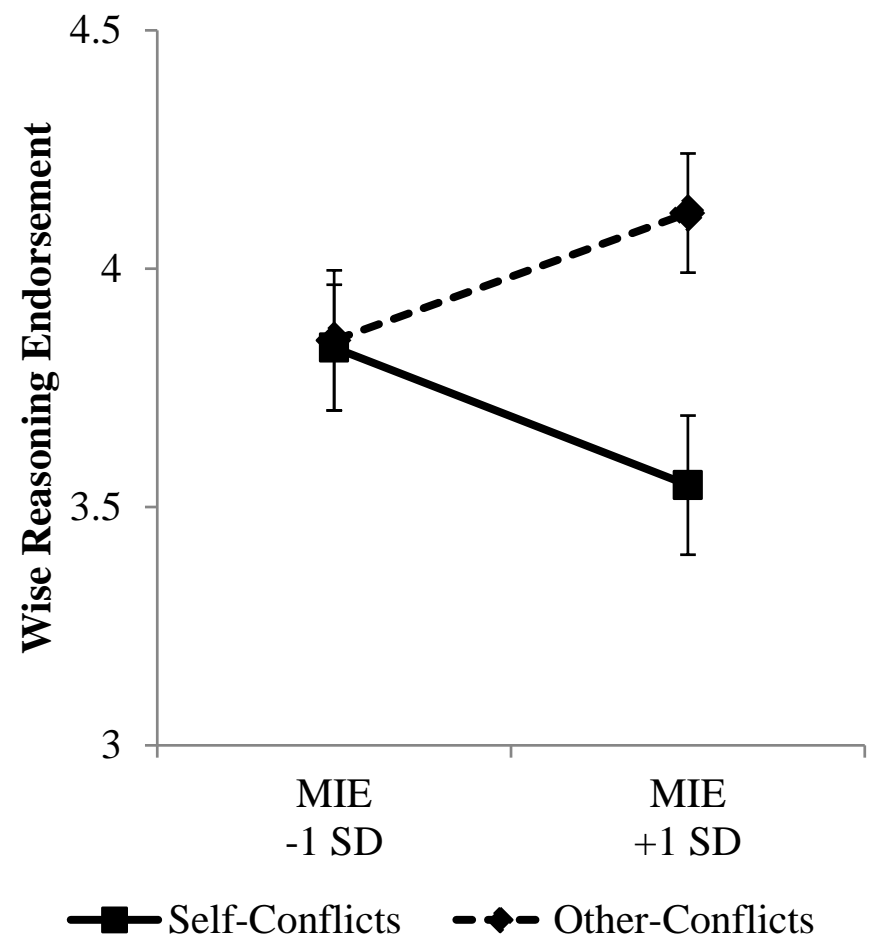

Figure S1. Endorsement of wise reasoning for self- and other-conflicts across MIE performance. Plotted at 1 standard deviation above and below the mean. Error bars represent the standard error of the mean. MIE = Mind-in-Eyes performance. 
Table S1

Descriptives and Zero-Order Correlations Between Measures of Interest.

\begin{tabular}{|c|c|c|c|c|c|c|c|c|c|c|c|}
\hline \multirow{2}{*}{ Measures } & \multirow{2}{*}{$\begin{array}{l}\text { Study } 1 \\
M(S D)\end{array}$} & \multirow{2}{*}{$\begin{array}{l}\text { Study } 2 \\
M(S D)\end{array}$} & \multicolumn{9}{|c|}{ Correlations } \\
\hline & & & 1 & 2 & 3 & 4 & 5 & 6 & 7 & 8 & 9 \\
\hline 1. Pursuit of Virtue & $4.44(.55)$ & $4.18(.70)$ & - & $.42^{* * *}$ & $.44^{* * *}$ & .14 & $.16^{* *}$ & $.26^{* * *}$ & .003 & - & - \\
\hline 2. Pursuit of Hedonia & $4.34(.54)$ & $4.07(.72)$ & $.43^{* * *}$ & - & $.27^{* *}$ & .14 & -.04 & $.27^{* * *}$ & -.01 & - & - \\
\hline 3. Wise Reasoning (self-conflicts) & $3.70(.69)$ & $3.79(.81)$ & $.39^{* * *}$ & $.20^{* * *}$ & - & - & .04 & .18 & $-.20^{*}$ & - & - \\
\hline 4. Wise Reasoning (other-conflicts) & $3.99(.61)$ & $3.85(.84)$ & $.31^{* * *}$ & $.20^{* * *}$ & $.65^{* * *}$ & - & .04 & $.15^{\dagger}$ & $.22^{*}$ & - & - \\
\hline 5. Steger's Presence of Meaning & $3.08(.88)$ & $3.51(.95)$ & $.11^{*}$ & .04 & .08 & $.15^{* *}$ & - & $-.38^{* * *}$ & -.10 & - & - \\
\hline 6. Steger's Search for Meaning & $3.79(.82)$ & $3.21(1.04)$ & $.29^{* * *}$ & $.21^{* * *}$ & $.13^{*}$ & .07 & $-.45^{* * *}$ & - & -.01 & - & - \\
\hline 7. Mind-in-Eyes Test & $24.49(4.08)$ & $24.36(6.10)$ & .02 & -.02 & -.03 & -.01 & -.07 & -.03 & - & - & - \\
\hline 8. Emotional Intelligence & -- & $3.70(.52)$ & $.29^{* * *}$ & $.29^{* * *}$ & $.30^{* * *}$ & $.24^{* * *}$ & $.31^{* * *}$ & .02 & $.18^{* *}$ & - & - \\
\hline 9. PANAS (pos-neg diff. score) & -- & $1.34(1.28)$ & $.21^{* * *}$ & .07 & $.11^{*}$ & $.14^{* *}$ & $.38^{* * *}$ & $-.17^{* *}$ & -.003 & $.26^{* * *}$ & - \\
\hline 10. Self-Esteem & -- & $3.84(.84)$ & .09 & .04 & .04 & .02 & $.60^{* * *}$ & $.31^{* * *}$ & .09 & $.35^{\text {**** }}$ & $.55^{* * *}$ \\
\hline
\end{tabular}

Note. Correlations for Study 1 are presented above the diagonal. Study 2 correlations are presented below the diagonal. Mind-in-eyes test scores reflect the number of correct responses out of 36. Pursuit of virtue and pursuit of hedonia reflect their mean values prior to residualizing out the other. Self-conflicts and other-conflicts are between-subjects in Study 1 and repeated measures in Study 2. $\dagger p<.10 ;{ }^{*} p<.05 ;{ }^{* *} p<.01 ;{ }^{* * *} p<.001$ 
Table S2

Subcomponents of the 19-item Wise Reasoning Scale

1. Considering Others' Perspectives

a. Trying to put myself in the other person/people's shoes.

b. Trying to communicate to find common ground.

c. Making an effort to take the other person's perspective.

d. Taking time to get the others' opinions on the matter before coming to a conclusion.

\section{Intellectual Humility}

a. Double-checking whether my opinion on the situation might be incorrect.

b. Considering whether others' opinions might be more correct than mine.

c. Looking for any extraordinary circumstances that may have affected the situation.

d. Recognizing that there may be some important and relevant information that I do not know about.

\section{Search for Compromise}

a. Trying to find a way to accommodate both perspectives.

b. Searching for a solution that could result in both people being satisfied.

c. Considering whether a compromise is possible in resolving the situation.

\section{Adopting an Outsider's Perspective}

a. Trying to see the situation from the point of view of an uninvolved person.

b. Imagining what other people might think or feel if they were watching the situation.

c. Imagine whether an outside person might have a different opinion from mine.

\section{Recognition of Change}

a. Considering how the situation might change over time.

b. Looking for different solutions as the situation evolves.

c. Considering alternative solutions as the situation evolves.

d. Recognizing the situation could lead to a number of different outcomes.

e. Recognizing the situation could unfold in many different ways.

Note. The items used in our study were adapted from prior research on wise reasoning (Brienza, Kung, Santos, Bobocel, \& Grossmann, 2017). Participants completed these items on a scale from 1 (very useless) to 5 (very useful) with the following prompt: "Regarding the relationship difficulty that you just wrote about, please rate how useful the following courses of action might be if you were going to try to resolve the situation." 
Table S3

Psychometric Properties of the Wise Reasoning Measure in Studies 1 and 2

\begin{tabular}{|c|c|c|c|c|c|c|c|c|c|}
\hline \multirow[t]{2}{*}{ Subcomponent } & \multirow{2}{*}{$\begin{array}{c}N \\
\text { Items }\end{array}$} & \multirow{2}{*}{$\begin{array}{c}S 1 \\
\alpha\end{array}$} & $\begin{array}{l}\text { S2 } \\
\text { (Self) }\end{array}$ & $\begin{array}{c}\text { S2 } \\
\text { (Other) }\end{array}$ & \multicolumn{5}{|c|}{ Component Correlations } \\
\hline & & & $\alpha$ & $\alpha$ & 1 & 2 & 3 & 4 & 5 \\
\hline $\begin{array}{l}\text { 1. Considering } \\
\text { others' } \\
\text { perspective }\end{array}$ & 4 & .85 & .90 & .91 & - & .54 & .62 & .34 & .56 \\
\hline $\begin{array}{l}\text { 2. Intellectual } \\
\text { humility }\end{array}$ & 4 & .80 & .84 & .89 & $.65 / .80$ & - & .61 & .47 & .54 \\
\hline $\begin{array}{l}\text { 3. Search for } \\
\text { compromise }\end{array}$ & 3 & .83 & .87 & .90 & $.69 / .81$ & $.68 / .75$ & - & .40 & .55 \\
\hline $\begin{array}{l}\text { 4. Adopting an } \\
\text { outsider's } \\
\text { perspective }\end{array}$ & 3 & .84 & .89 & .91 & $.45 / .55$ & $.58 / .64$ & $.43 / .54$ & - & .34 \\
\hline $\begin{array}{l}\text { 5. Recognition of } \\
\text { change }\end{array}$ & 5 & .86 & .90 & .90 & $.64 / .74$ & $.59 / .68$ & $.70 / .71$ & $.45 / .51$ & - \\
\hline
\end{tabular}

Note. All correlations are significant at $\mathrm{p}<.001$. For Study 2 correlations, the second number after the forward slash reflects correlations for other-conflicts. 


\section{Table S4}

Results of PCA Analyses for Wise Reasoning Scale across Studies 1-2

\begin{tabular}{|c|c|c|c|c|}
\hline $\begin{array}{l}\text { Scale Item } \\
\text { (refer to Table S2 for specific item) }\end{array}$ & Component 1 & Component 2 & Component 3 & Component 4 \\
\hline \multicolumn{5}{|l|}{ Considering Others' Perspectives } \\
\hline 1a. & $.78[.58]$ & & $(-.91)$ & \\
\hline $1 b$. & $.82[.70]$ & & $(-.78)$ & \\
\hline $1 \mathrm{c}$. & $.95[.51]$ & & $(-.88)$ & \\
\hline $1 \mathrm{~d}$. & $.62[.46]$ & & $(-.60)$ & \\
\hline \multicolumn{5}{|l|}{ Intellectual Humility } \\
\hline $2 \mathrm{a}$. & & & & $-.86(-.46)[.69]$ \\
\hline $2 b$. & & {$[.33]$} & & $-.89(-.56)[.65]$ \\
\hline $2 c$. & & & & $-.57(-.81)[.59]$ \\
\hline $2 \mathrm{~d}$. & {$[.35]$} & & & $-.48(.76)[.44]$ \\
\hline \multicolumn{5}{|l|}{ Search for Compromise } \\
\hline $3 a$. & $.44[.82]$ & & & $-.48(-.44)$ \\
\hline $3 b$. & $.45(.40)[.92]$ & & & $-.32(-.47)$ \\
\hline $3 c$. & $.41[.80]$ & & $(-.34)$ & $(-.37)$ \\
\hline \multicolumn{5}{|l|}{ Adopting an Outsider's Perspective } \\
\hline $4 a$. & & $.84(.76)[.82]$ & & \\
\hline $4 \mathrm{~b}$ & & $.91(.92)[.96]$ & & \\
\hline $4 c$. & & $.84(.92)[.93]$ & & \\
\hline \multicolumn{5}{|l|}{ Recognition of change } \\
\hline $5 a$. & $(.79)$ & & $.68[.67]$ & \\
\hline $5 b$. & $(.81)$ & & $.81[.52]$ & \\
\hline $5 c$. & $(.84)$ & & $.76[.55]$ & \\
\hline $5 \mathrm{~d}$. & $(.72)$ & & $.84[.93]$ & \\
\hline $5 e$. & $(.71)$ & & .87 [.91] & \\
\hline
\end{tabular}

Note. This table reflects the Pattern Matrix obtained from a Principal Components Analysis of the 19-item wise reasoning scale, using a Direct Oblimin rotation. Refer to Table S2 for specific items. Both studies yielded 4 component solutions (Eigenvalue $>1.00$ ). Following suggestions from previous researchers (Tabachnick \& Fidell, 2001; Costello, \& Osborne, 2005), loading scores below .32 were suppressed and not presented. Numbers without brackets represent loadings from Study 1. Numbers in round brackets "( )" reflect Study 2 loadings for selfconflicts, and numbers in square brackets "[ ]" reflect Study 2 loadings for other-conflicts. 


\section{References}

Baron-Cohen, S., Wheelwright, S., Hill, J., Raste, Y., \& Plumb, I. (2001). The "Reading the Mind in the Eyes" test revised version: A study with normal adults, and adults with Asperger syndrome or high-functioning autism. Journal of Child Psychology and Psychiatry, 42, 241-251.

Brienza, J., Kung, F. Y. H., Santos, H. C., Bobocel, D. R., \& Grossmann, I. (2017, June 1). Wisdom, bias, and balance: Toward a process-sensitive measurement of wisdom-related cognition. Retrieved from osf.io/preprints/psyarxiv/p25c2

Cialdini, R. B., Trost, M. R., \& Newsom, J. T. (1995). Preference for consistency: The development of a valid measure and the discovery of surprising behavioral implications. Journal of Personality and Social Psychology, 69, 318-328.

McGregor, I., Zanna, M. P., Holmes, J. G., \& Spencer, S. J. (2001). Compensatory conviction in the face of personal uncertainty: Going to extremes and being oneself. Journal of Personality and Social Psychology, 80, 472-488.

Osborne, J. W., \& Costello, A. B. (2009). Best practices in exploratory factor analysis: Four recommendations for getting the most from your analysis. Pan-Pacific Management Review, 12, 131-146.

Rosenberg, M. (1965). Society and the adolescent self-image. Princeton, NJ: Princeton University Press.

Salovey, P., \& Mayer, J. D. (1990). Emotional intelligence. Imagination, Cognition and Personality, 9, 185-211.

Schutte, N. S., Malouff, J. M., Hall, L. E., Haggerty, D. J., Cooper, J. T., Golden, C. J., \& 
Dornheim, L. (1998). Development and validation of a measure of emotional intelligence. Personality and Individual Differences, 25, 167-177.

Steger, M. F., Frazier, P., Oishi, S., \& Kaler, M. (2006). The Meaning in Life Questionnaire: Assessing the presence of and search for meaning in life. Journal of Counseling Psychology, 53, 80-93.

Tabachnick, B. G., Fidell, L. S., \& Osterlind, S. J. (2001). Using multivariate statistics. Thompson, M. M., Naccarato, M. E., Parker, K. C., \& Moskowitz, G. B. (2001). The personal need for structure and personal fear of invalidity measures: Historical perspectives, current applications, and future directions. In Cognitive social psychology: The Princeton symposium on the legacy and future of social cognition (pp. 19-39).

Watson, D., Clark, L. A., \& Tellegen, A. (1988). Development and validation of brief measures of positive and negative affect: the PANAS scales. Journal of Personality and Social Psychology, 54, 1063-1070. 